\title{
Therapeutic Exercise and Hypertension
}

\author{
Lamina Sikiru \& Chuba G. Okoye
}

\begin{abstract}
Hypertension implies chronic elevation in SBP and DBP above levels considered desirable or healthy for the person's age and size. The focus of this review is to discuss the therapeutic efficacy of exercise on human hypertension. The paper revealed that hypertension is common among African, also that acute exercise raises the BP while exercise training (chronic exercise) reduces the $B P$ in hypertensive patients but may not reduce the BP of normotensive individual. Exercise function test and prescription were also highlighted. The paper concluded that therapeutic exercise is safe and effective in the management of hypertension. It was recommended that emphasis should be placed on therapeutic exercise in the management of hypertension in Africa.
\end{abstract}

Keywords: Therapeutic exercise; Systolic pressure; Diastolic pressure

\section{Introduction}

Hypertension or high blood pressure is a condition in which blood pressure is chronically elevated above levels considered desirable or healthy for a person's age and size. For the adult, a systolic blood pressure between 140 and $159 \mathrm{mmHg}$ or a diastolic blood pressure between 90 and $95 \mathrm{mmHg}$ is considered to be borderline hypertension, while a systolic and diastolic pressure of 160 and 96 $\mathrm{mmHg}$ respectively or greater is considered to be absolute hypertension. (Franklin, 2004; Chobanian et al., 2003; Guidelines Committee, 2003; World Health Organization[WHO], 1999).

Hypertension is classified as primary (essential) or secondary, the cause of primary hypertension, which accounts for the majority (95\%) 
of cases is unknown (idiopathic). However, there are factors leading to primary hypertension, they are called "Risk factors". These risk factors could be the result of genetic and environmental factors such as high level of sodium in diet, alcohol consumption, obesity, physical inactivity, age, and psychological stress, a combination of these factors or other factors yet to be substantiated or determined. The causes of secondary hypertension included endocrine and structural disorder such as congenital adrenal hypertension, Cushing syndrome, deoxycorticosteriod producing tumour, renin-secreting tumour, Little's syndrome and aldosteronism. (Kamide, 2003).

Hypertension is probably the most common cardiovascular disease, and major health problem all over the world (Gumells, 1974). It is a strong and independent risk factor for coronary heart diasease (National High Blood Pressure Education Programme, 1993) and the most important factor in stroke (America Heart Association. 1989). Epidemiological studies (Akinkigbe, 1972; $\quad$ Ekpo, 1992; Lawoyin et al., 1998) have consistently shown that hypertension is common among Africans (Akinkigbe, 1972;Ekpo, 1992; Lawoyin, et al.,1998; Idahosa, 1985).

Hypertension and its complications (stroke, congestive heart failure, kidney failure and heart attack) are largely responsible for morbidity and mortality in all age groups; it also creates major social, personal and financial problems, the cost of which is enormous (Akinpelu, 1990). Drug therapy remains the mainstay of hypertension management. However, antihypertensive drug is not without its side effects and long term complication, the difficulty of accepting lifelong drug therapy by as symptomatic hypertensive and high cost of drugs particularly in a depressed economy has led to the development of interest in searching for alternative non-pharmacologic management(Boyer \& Kasch, 1970). These approaches include low salt diet, meditation, relaxation, biofeedback and therapeutic exercise. Many studies (Boyer \& Kasch, 1970; Westheim et al., 1985; 
Hagberg,. \& Seals 1986); Smith et al.(2007), Westhoff et al (2007); Laterza et al (2007), Sohn, Hasnain and Sinacore (2007) have shown that exercise training lowers BP in Hypertensive patients. However in most cases, exercise alone will not reduce high blood pressure to normal level.

\section{Acute Exercise and SBP in Hypertension}

SBP above 140 to $160 \mathrm{mmHg}$ are considered hypertensive (Guidelines Committee, 2003; WHO, 1999; American College of Sports Medicine [ACSM],1995), because blood flow meets considerable resistance in the small capillaries and arterioles, blood must be pumped at high pressure to meet tissue demands. BP increases even more during exercise because tissue demands for blood are higher. Normally, the body can tolerate increasing BP during exercise. BP can reach dangerous levels in the hypertensive individual. Normally maximal SBP during exercise ranges between $150-220 \mathrm{mmHg}$. However, it is not uncommon for hypertensive people to exceed these values at rest and go considerably above them during exercise (Brooks, Fahey \& White, 1996). Exercise and exercise testing should stop if SBP is greater than 250mmtHg (ACSM, 1995).

\section{Acute Exercise and DBP in Hypertension}

DBP is particularly important because of its effect on coronary blood flow. DBP above 90-95 is considered hypertensive (Brooks, Fahey \& White 1996). During systole when the heart muscle is contracting, intramuscular vessels constrict, which leads to a reduction in blood flow. This means that the most significant amount of coronary blood flow occurs during diastole.During exercise, myocardial oxygen demand may increase five to six times above that at rest. If in hypertensive individual, diastolic pressure increases during exercise, then coronary blood flow could be compromised at a time when more blood is needed. This could create a relative ischemia, that is, more blood is needed than is delivered (Brooks, Fahey \& White, 1996). 
Increase in DBP during exercise of $15 \mathrm{mmHg}$ above rest have been found to be highly predictive of coronary artery disease (CAD) and to indicate greater severity of disease and more frequent left ventricular contraction abnormality(Brooks, Fahey \& White, 1996). Exercise and exercise testing should stop if DBP a greater than $120 \mathrm{mmHg}$ (ACSM, 1995).

\section{Role of Acute Exercise in Hypertension}

In general, patients with high resting BP have the highest SBP and DBP during exercise. However exercise blood pressure is a poor predictor of hypertension. Many subjects who have exaggerated BP responses to exercise will not develop hypertension. Resting BP decreases below the baseline following exercise. This is called postexercise hypotension; post-exercise hypotension is accompanied by decrease in epinephrine, dopamine, cortisol and sympathetic nervous system activity. The secretion of endogenous opiods and serotonin are related to the inhibition of sympathetic activity and reduced BP after exercise. The significance of post-exercise hypotension in the control of hypertension is unknown (Brook, Fahey \& White, 1996).

\section{Exercise Training (Chronic Exercise)}

In general, endurance exercise training reduces resting BP. Athletes and retired athletes have a much lower incidence of hypertension than do sedentary people ${ }^{1}$. Endurance training may moderately reduce blood pressure by 10mmHg (ACSM,1995; Pollock \&Wilmore, 1990). This reduction is possible by decreasing the activity of the sympathetic nervous system which may be due to increase in insulin receptor sensitivity and reduction of hyperinsulimia. Endorphin and serotonin secretion may play a role as well in exercise induced reduction in BP. Long time changes in blood vessel diameter induced by exercise training may also play a role(Brooks, Fahey \& White, 1996).

Not all patients will respond to endurance exercise with a decrease in resting BP. Non responders include patients with exaggerated exercise 
BP responses, decreased cardiac compliance and significant cardiac hypertrophy. Non-responders also do not show decreased catecholamine levels with training ${ }^{1}$. It is noteworthy that endurance training of individuals with normal $\mathrm{BP}$ fails to reduce their pressure to lower or subnormal level (Pollock \& Wilmore, 1990).

\section{Weight Training}

Weight training decreases BP in hypertensive patients. These results have been found for free weight training and circuit training. However, weight training can also result in explosive increase in BP, so caution is advised (Franklin, 2004). Low resistance with high repetition weight training is appropriate (Brooks, Fahey \& White, 1996).

\section{Treatment of Hypertension}

Secondary hypertension is curable, once the aetiology is removed either pharmacologically or surgically (Araoye, 200624). For idiopathic (essential) hypertension, there are two modes or approaches to the management:

(1) Drug management and

(2) Non-drug management.

Drug therapy remains the mainstay of hypertensive management. This may be administered singularly or in combination with other antihypertensive drugs. Various drugs employed in the management of hypertension. Antihypertensive drug therapy is not without its attending problems, such as troublesome side effects and long term complications such as hypokalemic, glucose tolerant impairement, increase in lipid concentration, reduced libido, parkinsonia signs, hyperlactinemia, headache, nausea, anorexia, palpitation, sweating, hyperglycemia, reflex tachycardial, dry cough, angioneuretic odema, rashes, loss of taste and abdominal pain (Araoye, 2006; Hanson , Lindolin \& Niskanen,1999; Shapiro \& Goldstein, 1982).Some antihypertensive drugs may even increase cardiovascular morbidity 
and mortality (ALLHAT, 2000;Grossman , Grossman , Schein , Zimlichman \& Gavish 2001; Cutler, 1998)

Owing to these various adverse effects of antihypertensive drugs, interest has arisen in searching for alternative non-pharmacological approaches to the management of human essential hypertension. Few of these approaches are counseling, dietary control and low sodium intake (less than $100 \mathrm{mmol}$ per day), weight reduction, reducing alcohol (less than 1 ounce ethanol, 24 ounce of bear and 8 ounce of wine etc per day)and smoking, exercise and relaxation (ACSM, 1995; Brooks, Fahey \& White,1996;WHO, 1978). The aim of hypertension management is to bring the standing BP below $140 / 90 \mathrm{mmHg}$ provided the side effects that can be tolerated (Brooks, Fahey \&White, 1996; Joint National Committee on Detection, Evaluation, 1993).

Studies have shown that exercise training lowers BP in hypertensive patients. However the use of therapeutic exercise alone or in combination with other hypertension management will depend on the stage and severity of the disease. The ACSM (1995) recommends the following:

\section{Individuals with high risk of developing hypertension:} Appropriate life style behaviour counseling and endurance training (therapeutic exercise) will reduce the rise in blood pressure that occurs with time, thus justifying the use of exercise as a non pharmacological strategy to reduce the incidence of hypertension in susceptible individuals.

\section{Individuals with mild to moderate hypertension:} Endurance exercise training will elicit an average reduction of $10 \mathrm{mmHg}$ for both SBP and DBP even greater reduction in BP in patients with secondary hypertension due to renal dysfunction. Exercise may be recommended as part of the initial treatment strategy for individuals with mild to moderate essential hypertension. 
3. Individuals with marked elevation in BP: Exercise should be added to their treatment regimen only after initiating pharmacologic therapy; exercise may reduce their BP further, allow them to decrease their antihypertensive medications and attenuate their risk for premature mortality.

\section{Functional Exercise Testing (FET) and Exercise Prescription}

Prior to exercise prescription the need for exercise functional test (stress test) is essential because heart failure can occur due to increased load on the heart from hypertension and from the effects of coronary disease. During exercise stress test, it is particularly important to take frequent measurements so that falling SBP can be noted immediately (Brooks, Fahey \& White 1996). FET is important because it provide data that are helpful in development of exercise prescription and risk stratification. Details of FET has been described elsewhere (ACSM,1995; Pollock \& Wilmore,1990).

Care must be taken when prescribing exercise to patients with hypertension. Though exercise is sometime used as an adjunct treatment of the disease, utmost caution should be used in its application, whereas exercise training tends to lower resting BP, acute exercise raise it. During or after exercise, hypertensive patients may be more susceptible to heart failure, coronary ischaemia, angina, claudication and possibly stroke.

In March 2004, the American College of Sports Medicine published their latest recommendations regarding exercise and hypertension. The "prescription" for exercise consists of 4 elements, represented by the acronym "FITT": frequency, intensity, time, and type.

Frequency: exercise should occur on most, preferably all, days of the week. 
Intensity: exercise intensity should be moderate (ie, $40-60 \%$ of $\left.\mathrm{VO}_{2} \max \right)$.

Time: duration of exercise should be at least 30 minutes per day; this can be achieved in one continuous session, or, sum of smaller periods of exercise throughout the day.

Type: endurance (aerobic) exercise such as walking, jogging or swimming are recommended. and preferred, but resistance exercise should not be ignored (Pescatello, Frank, Farqubar, Kelley \& Ray 2004).

Warm up is very important to avoid sudden high intensity which can result in explosive increase in BP that can compromise coronary artery blood flow. Cool down is also important because it allows metabolic system to gradually decrease to resting condition in a deliberate manner (Noble, 1986).

\section{Mechanism of Antihypertensive Effects of Aerobic Exercise}

The factor responsible for the potential antihypertensive effect of long term aerobic exercises are incompletely understood and unclear (Arakawa, 1993). However, it is theorized that the biochemical, neural, and hormonal changes in the blood vessel walls induce an acute and long-term blood vessel relaxation. When a person engaged in aerobic exercise, the SBP and HR will increase, while the DBP changes little, immediately following the exercise bout, the SBP of hypertensive individuals will fall below pre exercise values by 20-30 $\mathrm{mmHg}$ and that of normotensive individuals by $8-12 \mathrm{mmHg}$ an effect that lasts for 12 hours in healthy individuals and beyond 12 hours in hypertensive patients (MacDonald, Laing, Wilson \& Wilson, 1999; Halliwill, 2001). This decrease below the baseline following aerobic 
exerciseis called 'post exercise hypotension' (Brooks, Fahey \& White 1996).

There are many potential mechanisms responsible for the "post exercise hypotensive effects" including relaxation and vasodilatation of blood vessels in the legs and visceral organ areas (Halliwill, 2001).The blood vessels may relax after each exercise session because of body warming effects, local production of certain chemicals, such lactic acid and nitric oxide; decreases in nerve activity and changes in certain hormones and their receptors. Over time, as the exercise is repeated, there is growing evidence that a long lasting reduction in resting $\mathrm{BP}$ can be measured, which may be partly be due to the acute drop in BP that occurs after each bout (Hagberg, 1994).

Another mechanism is that the post exercise hypotension is accompanied by a decrease in serum cathecolamines, norepinephrine, dopamine, cortisol, sympathetic nervous system, plasma rennin activity (Brooks, Fahey \& White, 1996; Hagberg, 1994;38. Duncan , Farr \& Upton,1985;Nelson, Jannings , Esler \& Korner 1986). In addition to a reduction in sympathetic activities, a fall in plasma volume and cardiac index may also be important in the antihypertensive effect of aerobic exercise (Arakawa, 1993). Exercise has been reported to improve abnormal baroreflex function in patients with hypertension (Minami, 2003; Somers, Conway, Johnston \& Sleight, 1991).

Another possibility is that exercise training may decrease fat deposition, a factor linked to hypertension (Hagberg, 1994; Reid , Dart , Dewar \& Jennings 1994; Wadden , Foster , Letizia \& Mullen 1991).Regular aerobic exercise also provide other cardiovascular benefits. These include a fall in total cholesterol, an elevation in HDLCholesterol (Keleman, Effron, Valent \& Stewart 1990). 


\section{Conclusion}

The conclusion of this paper is that therapeutic efficacy and safety of exercise in the management of hypertension can be achieved only if medically prescribed, cautiously implemented and technically monitored. Also, aerobic moderate intensity exercise of between $40 \%$ - $60 \% \mathrm{VO}_{2}$ max of between 30-60 minutes per session of 3-5 sessions per week are effective exercise parameters in the management of hypertension.

\section{Recommendation}

The recommendation of this paper is that Africans should include therapeutic exercise in the global management of hypertension particularly in this depressed economic situation.

\section{References}

Akinkigbe, O.O(1972). High blood pressure in the African. London: Churchill Livingstone.

Akinpelu, A.O(1990). Beneficial effects of exercise training on human hypertension.Journal of Nig Soc of Physiotherapy. 10 (2): 28-30.

ALLHAT Collaboration Research Group (2000) Major cardiovascular Events in hypertensive patients randomized to doxagosin versus chlorthalidone: the antihypertensive and lipid lowering treatment to prevent heart attack trial(ALLHAT). JAMA 283: 1967 - 75.

American College of Sports Medicine(1995). ACSM's guidelines for exercise Testing and prescription. 5th ed. Baltimore: Williams and Wilkins, 1995.

America Heart Association. Heart facts(1989).Dallas TX: America Heart Association.

Arakawa k (1993)Antyhypertensive mechanism of exercise. $J$ Hypertens. 11:223

Araoye M.A. (2006) High blood pressure: the fact you must know. Medi.-Link Journal 6 (56) 10-17.

Boyer, J.L., Kasch, F.W(1970). Exercise therapy in hypertensive men. Journal of American Association of Medicine. 211: 1668-71.

Brooks, G.A., Fahey, T.D. \& White, T.P(1996). Exercise physiology: Human bioenergetics and its application. 2nd ed. Mountain View: Mayfield Publishing Company.

Chobanian A.V, Bakris G.L, Black H.R, Cushman W.C, Green L.A, Izzo J.L, Jones D.W, Materson B.J, Oparil S, Wright J.T, Rocella E.J, National 
High BP Education Programme Co-ordinating Committee (2003) The seventh Report of the Joint National Committee on prevention, Detection Evaluation and Treatment of high blood pressure. The JNC 7 report JAMA 289, 2560-2572.

Cutler J.A, (1998) Calcium- channel blockers for hypertensive uncertainty continues. N Engl J Med. 338 : 679-81

Duncan J.T, Farr J.E, Upton S.J (1985) The effects of aerobic exercise on plasma cathecplamines and blood pressure in patients with essential hypertension. JAMA 254:206.

Ekpo, A.R(1992). Demographic lifestyle and anthropometric correlates of blood pressure of Nigeria Urban civil servants, factory and plantation workers. Journal of Human Hypertension. 6 (4): 272-280.

Franklin S.S (2004) Systolic blood pressure its time to take control. American Journal of Hypertension 17 (12) 49s-54s.

Guidelines Committee (2003) European society of hypertension European society of cardiology guidelines for the management of arterial hypertension. $J$ Hypertens. 21-1011-53.

Grossman E, Grossman A, Schein MH, Zimlichman R and Gavish B (2001) Breathing control lowers blood pressure. J Human Hypertens 15: 26369.

Gumells, J.C(1974). Hypertensive vascular disease general comments. In: Gordon, M.S. (ed.). Self assessment in clinical cardiology. Chicago: Year Book Medical Publisher Inc.

Hagberg J.M (1994) Physical activity,physical fitness and blood pressure NIH consensus development conference: physical activity and cardiovascular health. Bathesda, MD, Office of the Director National Institute of Health. Pp69-71.

Hagberg, J.M. \& Seals, D.R(1986). Exercise training and hypertension. Acta Med Scand 1986; (suppl.) 711: 131-6.

Halliwill J.R (2001) Mechanisms and clinical implications of post exercise hypertension in human exercise and sports. Sci. Rev 29, 65.

Hanson L, Lindolin L.H and Niskanen L(1999) Effect of angiotensin convirtig enzyme inhibition compared with conventional therapy on cardiovascular morbidity and mortality in hypertension: the captopril prevention project(CAPPP) randomized trial. Lancet. 353: 611-16

Idahosa, P.E(1985). Blood pressure pattern in Urban Edos. Journal of Hypertension.3 (suppl 3), 5: 379-81.

Kamide K (2003) Efficiency of screening for primary aldosteronism by adrenocortical scintigraphy without discontinuing antihypertensive medication. American Journal of Heart 16 (9) 725-28. 
Keleman M.H, Effron M.B, Valent S.A and Stewart K.J (1990) Exercise training combined with antihypertensive drug therapy effects on lipid, BP, and left ventrical mass. JAMA. 263: 2766.

Laterza M.C, Demator L.D, Trombetta I.C, Braza A.M, Roveda F, Alves M.J, Negrao C.E and Rondon M.U (2007)Exercise training restores baroreflex sensitivity in never trained hypertensive patients. Hypertension. 49(6) 1298-306.

Lawoyin, T.O., Asum, M.C., Kaufman, J., Rotim, P., Owoaje, E., Johnson, L. \& Cooper, R(1998). Prevalence of cardiovascular risk factor in an African Urban Inner City Community. Nigeria New Now.

MacDonald M.B, Laing G.P, Wilson M.P and Wilson T.W, (1999) Prevalence and predictors of white coat response in patients with treated hypertension MAJ 161: 265-9.

Minami N, Yoshikawa T, Kataoka H, Mori N, Nagasaka M, Kurosawa H, Kanasawa M, Kohzuki .M(2003).Effect of exercise and $\beta$-Blocker on blood pressure and baroreflexes in spontaneously hypertensive rats. AJA 16:966-927.

National High Blood Pressure Education Programme(1993). The fifth report of the joint Committee or detection, evaluation and treatment of high blood pressure; Washington D.C.

Nelson L, Jannings GL, Esler MD, Korner PI(1986) Effect of changing levels of physical exercise on blood pressure and haemodynamics in essential hypertension. Lancet. 2:437.

Noble, B.J(1986). Physiology of exercise and sport. St Lois: Times Mirror/Mosby College Publishing.

Pescatello L.S, Frank B.A, Farqubar W.B, Kelley G.A, Ray CA (2004) American College of Sports Medicine Position Stand: exercise and hypertension. Med SC Sporte Exer. 36:533-553.

Pollock, M.L. \& Wilmore, J.H (1990). Exercise in health and disease:

Evaluation and prescription for prevention and rehabilitative. 2nd ed. Philadelphia:EB Saunders Company.

Reid C.M, Dart A.M, Dewar E.M, Jennings GL(1994) Interaction between the effects of exercise and weigh loss on risk factors,cardiovascular haemodynamics and left ventricular structure in overweight subjects.$J$ Hypertens. 12:291.

Shapiro D (Goldstein JB (1982) Behavioural perspectives of hypertension. Journal of Consulting Clinical Psychology 50, 841-858

Smith P.J, Blumenthal J.A, Babyk M.A, Georgiades A, Hinderlister A, Sherwood A (2007) Effects of exercise and weight loss on depressive symptoms among men and women with hypertensive. J Pschosome Res63(5) 463-9. 
Sohn A.J, Hasnain M, Sinacore J.M (2007) Impact of exercise(walking) on blood pressure levels in African American adults with newly diagonised hypertension. Ethn Dis.17(3)507-7.

Somers V.K, Conway J, Johnston J, Sleight P (1991) Effects of endurance training on baroreflex sensitivity and blood pressure in borderline hypertension. Lancet; 337:1363 - 1386.

The Fifth Report of the Joint National Committee on Detection, Evaluation and Treatment of High Blood Pressure (1993). Arch Int Med.153: 154-183.

Wadden T.A, Foster G.D, Letizia K.A, Mullen J.L(1991)Weihgt reduction and metabolic rate: Goodnews for the obese patient(letter). Gastroenterology. 100:1146.

Westhoff T.H, Franke N, Schmidt S, Valbracht-Israng K, Meissner R, Yildirim H, Schlattmann P, Zidek W, Vandergiet M (2007) Too old benefit from sports?the cardiovascular effects of exercise training in elding subjects treated for isolated systolic hypertension. Kidney Blood Press Res.30(4):240-7.

Westheim, A., Simonsen, K., Scnameum, O., Miller, O., Stokke, O,

Tensberg, H(1985). Effect of exercise training in patients with essential hypertension. Journal of Hypertension.3 (suppl 3): 479-81.

World Health Organization(1978). Arterial Hypertension - Report of a WHO Expert committee Technical Report Series. In: Gross, F.H., Robertson, J. I.S. (eds.) Arterial Hypertension - The gestation and birth of a WHO Expert Committee. Kent: Pitman Medical Publishing Co. Ltd. Pp227265.

World Health Organization (1999) Hypertension practice guidelines for primary care. Physician. 2-9. 